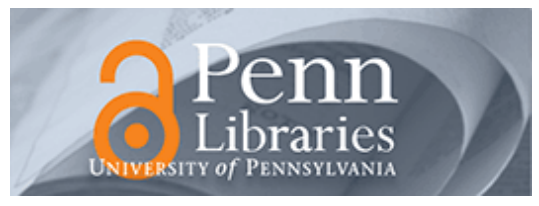

University of Pennsylvania

ScholarlyCommons

5-3-2019

\title{
A dimensional risk approach to assessing early adversity in a national sample
}

Sharon Wolf

University of Pennsylvania,wolfs@upenn.edu

Noelle Suntheimer

University of Pennsylvania, noellem@upenn.edu

Follow this and additional works at: https://repository.upenn.edu/gse_pubs

Part of the Developmental Psychology Commons, Early Childhood Education Commons, Policy Design, Analysis, and Evaluation Commons, and the Quantitative Psychology Commons

\section{Recommended Citation}

Wolf, S., \& Suntheimer, N. (2019). A dimensional risk approach to assessing early adversity in a national sample. Journal of Applied Developmental Psychology, 62 270-281. http://dx.doi.org/10.1016/ j.appdev.2019.03.004

This paper is posted at ScholarlyCommons. https://repository.upenn.edu/gse_pubs/573

For more information, please contact repository@pobox.upenn.edu. 


\title{
A dimensional risk approach to assessing early adversity in a national sample
}

\begin{abstract}
We examine how incidence and accumulation of two domains of risk factors-deprivation and threat of harm-predict early childhood development, testing a framework put forth by McLaughlin and Sheridan (2016). Using the ECLSK: 11 ( $N=18,200, M=5.6$ years; $48.7 \%$ female), a nationally representative sample of kindergarteners, we consider behavioral and cognitive indicators that represent different learning processes. We find partial support for the hypothesis that deprivation (but not threat) risks predict higherorder learning outcomes, with both incidence and accumulation of risk negatively predicting reading scores but mixed associations for executive function outcomes. We find support that incidence of threat (but not deprivation) risks negatively predict emotional and behavioral outcomes as hypothesized. When modeled cumulatively, however, both deprivation and threat risks predict behavioral outcomes. Finally, in line with hypothesized processes, both deprivation and threat risks negatively predict math scores, which represent pattern-learning processes. Implications for research in childhood adversity are discussed.
\end{abstract}

\section{Keywords}

Cumulative risk, Deprivation, Threat, Learning processes, Kindergarten

Disciplines

Developmental Psychology | Early Childhood Education | Education | Policy Design, Analysis, and Evaluation | Quantitative Psychology 


\section{Introduction}

The successful transition to kindergarten requires a multitude of early learning and behavioral skills (e.g., Duncan et al., 2007). Inequalities in children's early skills have been identified based on family disadvantages such as income (e.g., Reardon, 2011), and environmental disadvantages such as exposure to neighborhood violence (McCoy, Raver, \& Sharkey, 2015). While most research has considered disparities in early development based on a single factor, because risks are highly clustered this approach can overestimate the importance of individual risks. A cumulative risk approach assesses the number of disadvantages across multiple risks (Evans, Li, \& Whipple, 2013). There is widespread agreement that adverse early experiences exert profound influence on children's development, and research in the past decade has begun to untangle how that influence is exerted.

A risk factor can be defined as an individual or environmental factor associated with the increased likelihood of developing negative or maladaptive outcomes. Optimal child development rests on a wide range of inputs, such as adequate nutrition, exposure to language, and a responsive caregiver. Risk factors can be in the form of a single event that severely disrupts children's environment (e.g., sexual abuse) or prolonged over an extended period of time (e.g., chronic poverty). Importantly, there is not widespread agreement on how to define risk factors, and the way risk is operationalized varies across studies (Evans et al., 2013; Green et al., 2010) and disciplines (e.g., Bethell, Simpson, \& Solloway, 2017). At the core is a lack of stimulation, safety, and nurturance for the child, which requires significant psychosocial adaptations to unexpected stressful environments (i.e., adjusting to deviations from an “expectable environment"; Fox, Levitt, \& Nelson, 2010). The fields of child development and developmental neurobiology have begun to shed light on underlying mechanisms, allowing for more nuanced hypotheses about the ways in which different types of disadvantage may affect 
distinct learning processes and child functioning (e.g., McLaughlin \& Sheridan, 2016).

Specifying how risks pose different deviations from the expectable environment allows for a fuller understanding of the types of adjustments children may make when facing different types of adversity, the consequences, and potential targeted intervention strategies.

In this study, we build on the fields of cumulative risk and developmental neurobiology, as well as decades of research on poverty, adversity, and child development, to test how the incidence and accumulation of exposure to disadvantages in two areas - deprivation and threat of harm—are associated with different domains of children's school readiness skills in a nationally representative sample of kindergarteners. We focus on the kindergarten school year given that this developmental period consists of rapid growth in cognitive and social-emotional skills. This growth reflects both increasing environmental demands for these skills (e.g., in the context of classrooms), as well as children's increasing neurodevelopmental capacity for higher-order thinking (Shonkoff \& Phillips, 2000; Zelazo \& Carlson, 2012). Furthermore, children’s kindergarten academic and behavioral skills have lasting consequences for their long-term academic and social outcomes (e.g., Duncan et al., 2005; Jones, Greenberg, \& Crowley, 2015). Exposure to early risk factors may disrupt the development of such skills, thus disrupting the transition to school. This may partially explain for the link between early adversity and poor academic achievement.

\section{A Cumulative Risk Perspective on Disadvantage}

Across studies, the incidence of risk is predictive of poor outcomes. Yet children who experience one risk factor are likely to experience multiple risk factors (Green et al., 2010). A cumulative risk approach posits that no one risk factor is necessarily more harmful than another based on its content. Rather, it is the accumulation of risk, or the exposure to multiple stressors, that overwhelms adaptive capacities (Evans et al., 2013). A cumulative risk approach assumes a 
dose-response function-i.e., as the number of risk factors encountered increases, the severity of impact rises. But this is only true across all dichotomized risks, and the severity and frequency of exposure to each individual risk factor is not considered. This is an important limitation of the approach.

Nonetheless, it has been argued that cumulative risk models provide a more comprehensive representation of the overall levels of adversity faced by children (Luthar, 1993). In developmental psychology, work in this area began when researchers identified that a multiple risk index explained substantially more variance in children's development than a single risk factor alone (e.g., Sameroff, Seifer, Barocas, Zax, \& Greenspan, 1987; Sameroff, Seifer, Baldwin, \& Baldwin, 1993). Associations between cumulative risk and child development have been identified across a range of outcomes including psychological distress (e.g., Gabalda, Thompson \& Kaslow, 2010; Sameroff et al., 1987), learned helplessness (Evans, 2003), substance use (Newcomb, Maddahian \& Bentler, 1986), and academic outcomes (Luster \& McAdoo, 1994; Furstenberg et al., 2009), as well as across different developmental stages of childhood (for a full review, see Evans et al., 2013). The medical literature has focused on the accumulation of Adverse Childhood Experiences (ACES) in the home and family as they relate to negative health outcomes across the life span (e.g., Bethell et al., 2017). Bronfenbrenner's (1979) bioecological model of human development has been a starting point for examining risk at different levels of the environment (e.g., family, school, neighborhood), and other frameworks have put forward specifying psychosocial and physical dimensions of these environments that might pose risks (e.g., safety, noise, housing quality; Evans, 2006).

Building on these findings, studies have begun to identify physiological mechanisms through which risk is thought to affect child development, namely increased stress and allostatic load. Allostasis refers to the neural or neuroendocrine adaptation to stress, while allostatic load 
refers to the physiological consequences of chronic neural or neuroendocrine response adaptations resulting from repeated or chronic stress. The result is physiological changes that are adaptive in the short term but maladaptive in the long term (McEwen, 2012), and can become what is referred to as toxic stress (Shonkoff et al., 2012). From both perspectives, the accumulation of stressful events, or the experience of chronic stress, would be expected to have more harmful consequences than infrequent stressful events. The implications of these frameworks for intervention are primarily limited to reducing exposure to all risks.

\section{A Dimensional Approach to Cumulative Risk: Threat and Deprivation}

Neurobiological evidence has focused primarily on the role of single risk factors. McLaughlin and Sheridan (2016) advance an alternative cumulative risk model that differentiates between two dimensions of risk and moves beyond stress to focus on how risks can affect learning processes and their underlying neural correlates. Deprivation risks refer to experiences related to a lack of expected cognitive and social inputs from the environment, while threat risks refer to experiences involving harm or threat of harm (McLaughlin \& Sheridan, 2016). While both types of risk disrupt the expected environment (Fox et al., 2010), they may affect development differently. Deprivation risks relate to the lack of an expectable environment of cognitive stimulation, leading to the development of neural structures designed for environments that lack complexity and stimulating interactions (McLaughlin \& Sheridan, 2016). Deprivation risks include lack of basic necessities such as food and shelter, materials with which to engage, cognitively stimulating experiences in and out of the home, and close relationships with adults. These experiences constrain basic forms of learning that depend on sensory and social inputs, including implicit learning, through the development of neural structures designed for non-complex environments. Higher-order learning processes, such as long-term memory, executive functions, and general academic achievement would be affected as a result 
(McLaughlin \& Sheridan, 2016).

Threat risks, on the other hand, may affect neural circuits underlying emotional learning processes, which shape emotions and behaviors and include fear conditioning. Understanding safety and danger cues in the environment is critical for survival. Yet variation exists in children's ability to do so based on their early experiences with threats to their safety. Disruption in the neural circuits that detect environmental cues would underlie this variation, as childhood threat may be associated with heightened reactivity and a decreased ability to regulate emotional responses (Lambert. King, Monahan, \& McLaughlin, 2017; McLaughlin et al., 2016).

Studies have supported some of the underlying neurological pathways related to these associations. For example, amygdala volume - the part of the brain involved with the experience of emotions - has been found to be negatively associated with fear responses to threat cues during fear conditioning tasks (Hartley, Fischl, \& Phelps, 2011; Lupien, McEwan, Gunnar, \& Heim, 2009). Furthermore, in a sample of children ages 9-13 years, early—but not later-lifeexperiences of stress associated with financial deprivation were negatively associated with bilateral hippocampal volume, an area of brain associated with memory and implicit learning (Humphreys et al., 2018). These findings support the notion that associations between early experiences and developmental outcomes may be mediated by a developing brain that is adapted to particular environmental conditions.

Elements of the model have been recently tested in applied studies and provide further supportive evidence, primarily with adolescents. For example, Miller and colleagues (2018) found that adolescents who had experienced higher levels of deprivation before age six had higher externalizing behaviors at age 17. This longitudinal association was mediated through decreased verbal abilities at age 14, suggesting that deprivation risks led to lower verbal abilities, which subsequently led to behavior problems. In a study focused on executive function, 
Sheridan, Peverill, Finn, \& McLaughlin (2017) found that adolescents' parent-reported executive function was predicted by neglect and parental education but not abuse or community violence. These findings replicated in lab-based tasks, where abuse exposure was not associated with task performance or neural recruitment, supporting the theory that deprivation, but not threat-related experiences, would affect executive function development. Busso, McLaughlin, \& Sheridan (2017) found that among adolescents, both deprivation (measured by poverty status) and threat (measured as exposure to interpersonal violence) were associated with higher levels of psychopathology in adolescence. However, only exposure to threat was associated with differences in physiological reactivity, which mediated the association between threat and externalizing psychopathology. Finally, Heleniak, King, Monahan, \& McLaughlin (2018) found that exposure to community violence was associated with higher levels of internalizing symptoms in adolescence, which was mediated by greater emotional arousal.

Whether similar associations are evident earlier in life has not been studied as systematically within this framework. But decades of studies across diverse samples have identified the link between economic deprivation and disparities in young children (e.g., McLoyd, 1998; Duncan \& Brooks-Gunn, 1997; Duncan, Yeung, Brooks-Gunn, \& Smith, 1998), and that increasing stimulation and inputs can support development across a range out short- and long-term outcomes (e.g., Olds, Sadler, \& Kitzman, 2007). Moreover, previous studies have identified unique associations between poverty, parental investments, material hardship, and parental stress, for example, with different domains of child development (e.g., Gershoff, Aber, Raver, \& Lennon, 2007; Kainz, Willoughby, Vernon-Feagans, \& Burchinal, 2012; Rhoades, Greenberg, Lanza, \& Blair, 2011). Similarly, studies have found that experiences that threaten children's safety such as inter-parental aggression, abuse, and neglect in early childhood undermine children's attention (e.g., Towe-Goodman, Stifter, Coccia, \& Cox, 2011) and 
behavioral outcomes (Gilbert et al., 2009). Importantly, despite the rich research base, few studies to date examining cumulative risk have differentiated between the accumulation of different types of risks. Taken together, these studies provide a platform from which to consider cumulative disadvantages across the two areas of deprivation and threat in early childhood.

Higher-order learning outcomes. Higher-order developmental skills are considered central to children's school success, including cognitive control, memory, and reading skills. McLaughlin \& Sheridan (2016) posit that these outcomes would be most sensitive to experiences of deprivation. Socioeconomic status has been shown to be associated with observed outcomes and the underlying neurocognitive systems for each of the three (see Noble, Tottenheim \& Casey, 2005 for a review), as have other forms of deprivation. For example, several groundbreaking studies on children reared in deprived institutional settings demonstrated that institutionalized children were found to perform more poorly in inhibitory control tasks, but not in planning and rule acquisition, when compared to children who were not institutionalized (Pollak et al., 2010). Previous work has also established differences in language development (Whitehurst, 1997) and executive function systems across socioeconomic statuses in young children (Noble, Norman \& Farah, 2005; Noble, McCandliss, \& Farah, 2007). Furthermore, Roy \& Raver (2014) found that in a sample of low-income children, those who experienced deep poverty and crowded household conditions had worse academic performance than low-risk children or children in high-stress households but not experiencing deep poverty or crowding. Underlying the development of both executive functions (Diamond, 2013) and early literacy and language development are reward-learning processes (Hackman \& Farah, 2009; Noble et al., 2007). These processes relate to how children learn information from environmental stimuli and track the probability of rewards associated with particular cues. These learning processes influence actions in anticipation and receipt of rewards and allow children to modify 
their behavior in situations with novel rewards (e.g., executive functions; Berridge \& Kringlebach, 2008). The ability to detect patterns across environmental stimuli has also been linked to language acquisition and development (Romberg \& Saffran, 2010). Disruptions in the neural circuitry that supports reward-learning have been found in institutionally reared children experiencing extreme deprivation (Mehta et al., 2010), and in adolescents who experienced neglect (Hanson, Hariri, \& Williamson, 2015). In lab-based studies assessing reward-learning tasks, where children learn to respond in particular ways to various cues, those raised in deprived institutional settings do not show the same response pattern as typically developing childrenthat of faster and more accurate responses to cues associated with high rewards (Sheridan, Fox, Zeanah, McLaughlin, \& Nelson, 2012).

Studies to date have primarily examined one type of deprivation as it is associated with higher-order learning outcomes. In this study, we extend this literature to consider deprivation as both incidental and cumulative, and consider deprivation experiences (e.g., low levels of parental warmth and lack of engagement in cognitively stimulating activities) as well as factors that have been found in previous studies to be related to deprivation experiences. This includes single parenthood (e.g., Amato, 2005), financial hardship (e.g., McLoyd, 1998; Gershoff et al., 2007), material deprivation (poverty status, e.g., Brooks-Gunn \& Duncan, 1997; food insecurity, (Johnson \& Markowitz, 2018), lack of school involvement (Hill \& Tyson, 2009), low parental warmth and maternal depression (e.g., Cummings \& Davies, 1994; Davidov \& Grusec, 2006; Petterson \& Albers, 2001), lack of engagement in cognitively stimulating activities (Bradley \& Corwyn, 2002), minimal reading to child at home (e.g., Mol, Bus, deJong, Smeets, 2008; Sénéchal \& LeFevre, 2002), lack of participation in extracurricular activities (e.g., Mahoney, 2000), and a high number of parental work hours, which may be related to reduced time spent with children (Ermisch \& Francesconi, 2002; Kalil, Dunifon, Croskey, \& Su, 2014) and has been 
identified as a risk for language development (Odom, Vernon-Feagans, \& Crouter, 2013).

Our inclusion and categorization of such risks was partly driven by considering the necessary skills for children to have acquired at the start of kindergarten. For example, while reading is a cognitively stimulating activity, we distinguish between reading and cognitively stimulating activities outside the home, such as going to the zoo, given that early literacy skills are distinct and important for the transition to kindergarten (e.g., Duncan et al., 2007). Research has shown that parents reading to their child is directly linked to verbal abilities and early reading skills (e.g., Sharif, Rieber, Ozuah, \& Reiber, 2002; Zuckerman, 2009).

Emotions and behaviors. McLaughlin \& Sheridan (2016) posit that emotional-learning would be most sensitive to experiences of threat. Research on children who experienced abuse show that they are more likely to react variably to emotional stimulation, and differently from neglected and non-abused children (Pollak et al., 2000), demonstrating potential differences in how children view the world and respond to emotional cues. Studies on exposure to violence show that community violence can impact children's attentional focus (McCoy et al., 2015) and attention control (Raver, McCoy, \& Lowenstein, 2013). Additionally, in a sample of low-income and poor preschoolers, children who lived in a household that reported high stress had more behavior problems than low-risk children or children experiencing deprivation (measured via deep poverty) but low reported stress (Roy \& Raver, 2014).

Based on available data and previous research, we consider dimensions of threat risks related to the safety of children's home neighborhood (Burdette \& Whitaker, 2005; To, Cadarette, \& Liu, 2001) and school neighborhood (Bowen \& Bowen, 1999; Herrenkohl et al., 2000; Reich, Culross, \& Behrman, 2002), use of corporal punishment at home (Gershoff, 2002) and harsh disciplinary practices (Chang, Schwartz, Dodge, \& McBride-Chang, 2003; Weiss, Dodge, Bates, \& Pettit, 1991), high parenting stress (Neece, Green, \& Baker, 2012), which can 
compromise healthy family functioning as parents may be more likely to resort to harsh punishment (Deater-Deckard, 2005), parent substance abuse (Smith \& Wilson, 2016), and high home mobility (Jelleyman \& Spencer, 2008; Scanlon \& Devine, 2001), which has been shown to undermine children's sense of safety (Mollborn, Lawrence \& Root, 2018).

Pattern learning outcomes. Pattern learning processes draw on an individual's knowledge and experience to make connections and discover patterns between cues in the environment and particular outcomes. McLaughlin and Sheridan (2016) hypothesize that that both deprivation and threat risks might affect outcomes related to pattern learning processes. These learning processes refer to ability to detect regularities in the environment that are not necessarily linked to rewards or punishment and understand and predict the environment. They are drawn upon heavily when learning mathematics skills (e.g., Tatsuoka, Corter, \& Tatsuoka, 2004; Mulligan \& Mitchelmore, 2009), and some have argued that they are closely linked to implicit learning (Perruchet \& Pacton, 2006), for example, in language acquisition (Romberg \& Saffran, 2010).

While this is the least studied area of the outcomes described, some suggestive evidence supports this hypothesis. For example, children's mathematics achievement hinges on a number of cognitive factors in addition to subject-specific numerical skills, including language (Donlan, Cowan, Newton, \& Lloyd, 2007), attitudes (Ma, 1999), and executive functioning (Yeniad, Malda, Mesman, van IJzendoorn, \& Pieper, 2013; Bull \& Scerif, 2001). Pattern learning processes have also been linked to children's emotional outcomes such as teacher-reported depression (Sheridan et al., 2016), suggesting that pattern learning draws on a range of skills that are sensitive to both deprivation and threat risks.

For a full discussion of these distinct learning processes, and a review of the animal and brain research underlying them, see Sheridan and McLaughlin (2014) and McLaughlin and 
Sheridan (2016).

\section{The Present Study}

While the decades of literature on risk, cumulative risk, and child development have been conducted across a diverse array of samples and populations, the deprivation and threat risk framework is more recent and has been primarily developed in the context of laboratory-based animal and brain science research (Sheridan \& McLaughlin, 2014). Our study builds on this work to apply measures of risk— - both incidence and accumulation — across both dimensions. We test hypotheses based on nine behavioral and cognitive outcomes of child development that were available in our dataset and represent the three domains of developmental outcomes under question in a nationally representative sample of kindergarteners. The behavioral and cognitive indicators are intended to represent the manifestation and result of underlying neurobiological processes in children's school environments, which are arguably more important indicators of young children's school adjustment.

We focus on children during their first year of elementary school, given the importance of development across the kindergarten year in shaping children's longer-term outcomes (e.g., Arnold \& Doctoroff, 2003; Duncan et al., 2007). This partly due to the fact that achievement is an iterative process, with more advanced material building on children's foundational knowledge in both academic and social skills (Entwisle \& Alexander, 1990). Controlling for children's skill level at school entry for each outcome, we hypothesize that by the spring of kindergarten:

Hypothesis 1: Incidence and cumulative deprivation (but not threat) risks will be negatively associated with higher order cognitive outcomes, including tasks associated with early reading skills and executive function skills (i.e., working memory, cognitive flexibility, and inhibitory control).

Hypothesis 2: Incidence and cumulative threat (but not deprivation) risks will be 
negatively associated with outcomes related to emotions and behaviors (i.e., externalizing behaviors, interpersonal skills, approaches to learning, and attentional focus).

Hypothesis 3: Incidence and cumulative threat and deprivation risks will be negatively associated with outcomes related to pattern and associational learning processes (i.e., math skills).

Finally, we also examine an exploratory research question assessing if there are interactive effects of deprivation and threat risks on each outcome.

\section{Methods}

\section{Participants and Protocol}

Data come from the Early Childhood Longitudinal Study-Kindergarten (ECLS-K) 2010 2011 Cohort, a nationally representative sample of approximately 18,200 U.S. kindergartners (Mulligan, Hastedt, \& McCarroll, 2012). The current study uses data from the fall (start of the year) and spring (end of the year) of kindergarten. In the fall, children were an average of 5.6 years old, 48.6\% female, 57.3\% White, 12.3\% Black, 21.5\% Hispanic, 3.5\% Asian, and 5.3\% “other" race.

Children, parents, and teachers participated in the study at the beginning of the kindergarten school year (Fall 2010) and again at the end of the school year (Spring 2011). At both Fall and Spring assessments, one parent was interviewed over the phone about each child's social-emotional competence and family experiences. The average length of interviews at each wave was 45 minutes. Teachers provided information on children's social-emotional competence in fall and spring through self-administered hard-copy questionnaires. Direct assessments of children's cognitive skills were obtained through untimed one-on-one Computer Assisted Personal Interviews (Mulligan et al., 2012).

\section{Measures}


Risk indices. The deprivation and threat risk indices were computed from the fall and spring parent interviews. We thoroughly examined the interview questions and created an extensive list of risk variables available in the public-use dataset. While there are no rigid rules or existing formula to define an experience as adverse, we drew on a large existing body of research on disadvantages and child development (e.g., Duncan \& Brooks-Gunn, 1997; Gershoff et al., 2007; Kainz et al., 2012; Rhoades et al., 2011). We then determined whether the risk was a threat to the child's physical integrity (e.g., unsafe neighborhood, parental use of corporal punishment) or if there was an absence of expected environmental inputs (e.g., poverty, low parental warmth) for optimal child development according to the threat and deprivation definitions put forth by McLaughlin and Sheridan (2016). All risks were dichotomized and summed within risk dimension as summarized in Table 1 and the bivariate correlations for all risks are displayed in Table 2. We reviewed the descriptive statistics and the correlations between risk factors to ensure there was not significant overlap across risks. Correlations ranged from -.14 to $.33(M=.07)$, suggesting that each risk could be considered independently. Table 1 presents the risk variables, definitions, and sample prevalence. The correlation between the deprivation $(M=1.6, S D=1.6$, range $=0-9)$ and threat $(M=1.1, S D=1.0$, range $=0-6)$ risk indices was $0.31(p<.001)$.

Deprivation risks. All deprivation risks were reported by the participating parent in the fall or spring interview in the kindergarten year. Eleven risks were considered (though no child had more than nine reported risks) and either summed to represent a cumulative deprivation risk index or dichotomized to represent incidence of deprivation risk (i.e., any deprivation risk or no deprivation risk). Below and in Table 1 outlines how each deprivation risk is defined.

Single parent household. The parent indicated that he/she did not have a spouse or partner that lived in the household. 
Financial hardship. The parent indicated that the family experienced serious financial problems or had trouble paying the monthly bills since the child was born.

Poverty. Parents reported their exact household income rounded to the nearest $\$ 1,000$, which was used to create the composite poverty variable in the dataset using the U.S. Census Bureau threshold for the household size.

No parent school involvement. Parent reported that he/she or other adults living in the household had not attended a regularly-scheduled parent-teacher conference or meeting.

Low levels of parental warmth. Parental warmth was assessed through four questions regarding their warmth and affection towards the child. The questions captured relationship warmth by asking, for example, if he/she often has warm, close times together with the child.

No family participation in cognitively stimulating activities with child. This risk variable is comprised of a set of six questions that ask if anyone in the child's family had participated in any of six activities in the past month (e.g., visited a library, gone to the zoo, gone to a play). If "no" was answered for all six items, we considered it to be a risk.

Minimal reading to child. Parent reported that the child did not look at picture books or read at home, either to him/herself or with others, in the past week.

No child participation in extracurricular activities. A subset of twelve items were considered in the development of this risk variable. These twelve questions asked about the child's involvement in a variety of activities outside of school hours, such as academic activities, dance lessons, and organized athletic activities. If the child had not participated in any of the twelve activities, we considered this to be a risk.

Maternal depression symptoms. Mothers of the child were asked a series of 11 questions to assess symptoms of depression during the past week. These questions asked how often mothers felt, for example, like not eating, as in if her appetite was poor; like she can't shake off 
the blues even with the help from family and friends; like she had trouble keeping her mind on what she was doing; and depressed. We calculated the bottom $15 \%$ of the sample and considered those children with mothers who expressed the most severe depression symptoms to be a risk.

Household food insecurity. The parent reported "usually true" or "sometimes true" that any of the following occurred over the past 12 months: (a) worried that food would run out and they would not have money to buy more; (b) worried that food would not last and there would not be money to buy more; and (c) the family could not afford to eat balanced meals.

High number of parental work hours. At least one parent reported working for pay more than sixty hours per week.

Threat risks. Most threat risks were compiled from parent interview questions throughout the child's kindergarten year, with crime in the school neighborhood being the one exception which was asked of the school administrator. Seven risk variables were considered (though no child had more than 6) and either summed to represent a cumulative threat risk index or dichotomized to represent incidence of threat risk (i.e., any threat risk or no threat risk).

Safety of home neighborhood. Parent reported one or both of the following two things were a "big problem" in their home neighborhood: (a) selling/using drugs or excessive public drinking; (b) burglary or robbery; or that it was "not at all safe" for the child to play outside during the day.

Crime near school. Crime near the school was determined to be a risk if the school administrator indicated it to be a "big problem" (vs. "somewhat of a problem" or "no problem").

High parenting stress. Parents were asked four questions about parenting stress and indicated whether each was "completely true", "mostly true", "somewhat true", or "not at all true". We considered a parent to be under high parenting stress if he/she answered, "completely true" or "mostly true" to all four items. Examples included that the parent feels like he/she is 
giving up more of his/her life to meet the child's needs, and is often feels angry with the child.

Use of corporal punishment. Parents were asked in an open-ended question the number of times they spanked the child in the past week. Responses ranged from 0 to 30 . If the parent indicated spanking the child at least once in the past week, this was categorized as a risk.

Use of harsh disciplinary practices. Parents were presented with the following vignette: "Most children get angry with their parents from time to time. If $\{C H I L D\}$ got so angry that (he/she) hit you, what would you do?" Parents were asked to respond "yes" or "no" to ten different disciplinary methods, four of which we determined would be considered harsh: (a) spank the child, (b) hit back, (c) make fun of child, or (d) yell at child or threaten him/her. If the parent responded "yes" to at least one of the four items, this was categorized as a risk.

Parent substance use in past year. The participating parent was asked if they felt, or if anyone suggested, that they needed professional help for emotional problems or for drug or alcohol use within the past twelve months. Additionally, the same question was asked of the child's biological father if the biological father was living with the child and was not the interviewee. A risk was defined if substance use was a problem for one or both parents.

High child mobility. Child has lived in 3 or more different residences for four or more months since he/she was born.

Child outcomes. Child outcomes included direct assessments (administered by a trained assessor) and teacher reports. More information on task descriptions and reliability of measures are available in Mulligan et al. (2012). In this study, all scores were standardized based on the sample to have a mean of 0 and a standard deviation of 1 to ease interpretation of results.

Reading skills. Items were developed specifically for use in the ECLS-K:2011. Some items were borrowed or adapted from published tests and others created by testing and curriculum specialists. The two-stage assessments were adaptive, routing children to the next 
stage based on their performance in the previous section. The reading test assessed knowledge of basic skills such as letter and word recognition, beginning and ending sounds, vocabulary, and passage comprehension ( $\alpha=0.95$ in fall and spring). We use the transformed theta scores, which represent latent ability scores (Mulligan et al., 2012).

Math skills. The math test evaluated understanding of numbers, geometry, spatial relations, and problem-solving skills ( $\alpha=0.92$ fall, 0.94 spring). We use the transformed theta scores, which represent latent ability scores (Mulligan et al., 2012).

Executive function. Three core factors of executive function were measured (Miyake et al., 2000). Children completed two executive function tasks, the Dimensional Change Card Sort (DCCS) and Numbers Reversed, to measure their cognitive flexibility and working memory, respectively. In the DCCS task, children were asked to sort 22 picture cards into the appropriate tray by color and then by shape. If the child successfully sorted at least four of the six cards by shape, they were advanced to a third and final round of sorting. In this final round, children had an additional rule to be mindful of when sorting the cards. The Numbers Reversed task required children to repeat strings of numbers orally in the reverse order in which they were presented. The task reached completion when the child incorrectly recited the numbers. A third measure of executive function, inhibitory control, was teacher-reported using the Short Form of the Children's Behavior Questionnaire and captured the child's ability to focus on the present environmental stimuli and refrain from responding inappropriately in the moment $(\alpha=0.87$ in fall and spring).

Externalizing behaviors. Externalizing behavior was measured by the Social Skills Rating Scale (SSRS), in which teachers reported how often the child demonstrated externalized problem behaviors. The five-item scale included questions about how frequently the child fights, argues, gets angry, acts impulsively, or disturbs ongoing activities. A higher score represented 
worse behavior ( $\alpha=0.88$ in fall and spring).

Approaches to learning. This child outcome comprised six items reported by the teacher measuring how often the child exhibits positive approaches to classroom learning, including task persistence, independence, and flexibility. The specific items asked how frequently the child demonstrates the following learning behaviors: keeps belongings organized; shows eagerness to learn new things; works independently; easily adapts to changes in routine; persists in completing tasks; and pays attention well. A higher score represents more positive approaches to learning ( $\alpha=0.91$ in fall and spring).

Attentional focus. Teachers reported on 6 questions from the Short Form of the Children's Behavior Questionnaire, which collects information on children's behavior including one's likelihood to hold and direct attention to present tasks such as: distraction when listening to a story; frequent inability to complete a task; and becoming overly absorbed and involved in activities. A higher score reflects more focused attention to environmental cues and tasks $(\alpha=$ 0.87 in fall and spring).

Interpersonal skills. Teachers reported on 5 items from the SSRS to assess children's ability to form and maintain healthy friendships; respond sensitively to the feelings of peers; and respects differences in others. Higher scores indicate that a child interacts with peers in a more positive manner ( $\alpha=0.86$ in fall, 0.87 in spring).

Covariates. All multivariate analyses included a set of covariates that were selected to measure family characteristics related to risk and children's outcomes. These characteristics were selected because they are largely considered "fixed" characteristics in that they are unlikely to change (rapidly) as a function of risk or disadvantage. Covariates included primary parent's education level (less than high school 2.7\%; high school diploma or equivalent 20.8\%; some college / vocational technical program 31.5\%; bachelor's degree or higher $35.0 \%$ ), if English 
was the primary language spoken in the home (97.1\%), urbanicity of the school (city $32.1 \%$; suburb 37.2\%; town 7.3\%; rural 23.0\%), child's race (White 50.7\%; Black 11.2\%; Hispanic 23.7\%; Asian 8.3\%; Other 6.2\%) and sex (48.7\% female), household income $(M=10.6, S D=$ 5.6 on a scale of $1-18$ in $\$ 5,000$ increments), child's age $(M=67.5$ months, $S D=4.4$ months $)$ mother's age $(M=34.5$ years, $S D=6.7$ years $)$, and number of children living in the household $(M=2.5, S D=1.1)$

\section{Analytic Plan}

To assess how the two dimensions of risk differentially predict outcomes, we estimated associations between deprivation and threat risks, controlling for covariates, on each of the child outcomes in the spring of the school year using ordinary least squares (OLS) regression analysis with a Huber-White correction to adjust the standard errors for clustering of children within schools. We tested the predictive strength of both incidence and accumulation of risk separately by conducting two sets of models: (a) relations between experiencing any risk in deprivation and in threat domains (an indicator of $1=$ yes or $0=$ no) to assess the pattern of associations among risk indices and outcomes, controlling for children's fall outcome scores (Model 1), and (b) relations between cumulative risk indices in each domain, representing risk as the number of risks experienced in each domain, controlling for children's fall outcome scores (Model 2). Both models follow the equation represented in Equation 1.

Given the descriptive nature of our analysis, we aim to reduce selection bias by implementing lagged models, which control for children's fall score on each outcome. Controlling for children's baseline scores, in addition to a range of family and child demographic covariates, adjusts for unobserved or omitted variables associated with the lagged outcome. This approach is recommended given that measures of each outcome are repeated exactly in the two waves (National Institute of Child Health and Human Development Early Child Care Research 
Network \& Duncan, 2003). These models are used to test our hypotheses.

$$
\text { SpringScore } \left.=\alpha+\beta_{1} \text { Deprivation }+\beta_{2} \text { Threat }+\beta_{3} \text { (Covariates }\right)+\beta_{4} \text { FallScore }
$$

For the research question on the interaction between deprivation and threat risk, an interaction term between deprivation and threat is added to the equation.

Children who were missing more than half of the deprivation risks ( 7 or more) or more than half of the threat risks ( 5 or more) of the risks were excluded from the analyses $(N=4,711$, $25.92 \% ; N=4,919,27.07 \%$, respectively). To address missing covariate data, we used Stata's multiple imputation by chained equations technique (Royston, 2004) and created 20 imputed datasets. On average, $4.5 \%$ of cases were missing covariate data (ranging from $0-12.2 \%$ ). We follow best practice recommendations by Johnson and Young (2011) by using the full set of covariates, as well as the dependent variables, during imputation modeling. After imputation modeling, we exclude children who were missing dependent variable data (multiple imputation then deletion, or MID). All regression analyses were conducted using Stata's "mi estimate" command.

\section{Results}

Table 1 presents the sample prevalence of each risk index. It is notable that in this nationally representative sample of kindergarteners, nearly two-thirds $(65.8 \%)$ of children experience at least one threat risk, while $71 \%$ experience at least one deprivation risk. Over half $(50.4 \%)$ of children experience at least one threat and one deprivation risk.

\section{Incidence and Accumulation of Deprivation and Threat Risks}

Results from the multivariate regression analyses are displayed in Table 3. The first set of rows present the results from the first set of models examining how the incidence of deprivation and threat risks differentially predict children's outcomes in the spring of kindergarten. The first 
hypothesis - that the incidence of deprivation but not threat risk would predict reading scores and executive function skills - was partially supported. Specifically, reading scores were significantly negatively predicted by incidence deprivation only $(b=-0.030, S E=0.013, p<.05)$ and not by threat. However, none of executive function measures were predicted as hypothesized. Inhibitory control was significantly negatively predicted by both the incidence of deprivation $(b=-0.045, S E=0.016, p<.01)$ and threat risk $(b=-0.034, S E=0.015, p<.05)$, while cognitive flexibility and working memory were not significantly predicted by either.

The second hypothesis - that emotional and behavioral outcomes would be predicted by threat, but not deprivation risk, was fully supported. Specifically, incidence of threat but not deprivation risks predicted higher externalizing behaviors $(b=0.055, S E=0.014, p<.001)$, lower interpersonal skills $(b=-0.045, S E=0.016, p<.01)$, lower approaches to learning $(b=$ $0.040, S E=0.015, p<.01)$, and lower attentional focus $(b=-0.049, S E=0.016, p<.01)$.

Finally, the third hypothesis - that math scores, representing pattern-learning outcomes, would be negatively predicted by both deprivation and threat incidence, was supported $(b=$ $0.030, S E=0.012, p<.05$, and $b=-0.039, S E=0.011, p<.001$, respectively).

The second set of models assessed how the accumulation of deprivation and threat risks predict outcomes, following recommended conceptualizations of risk as cumulative (e.g., Evans et al., 2013; McLaughlin \& Sheridan, 2016). When modeling cumulative risk, six of the nine outcomes were predicted by both cumulative deprivation and threat risk indices, providing less support for the distinct hypothesized relations. The results are presented in the second set of rows in Table 3. The first hypothesis that deprivation but not threat risks would predict executive function and reading scores was supported in two of the four outcomes assessed. Specifically, each additional deprivation risk negatively predicted working memory $(b=-0.017, S E=0.006, p$ $<.01)$ and reading scores $(b=-0.023, S E=0.005, p<.001)$, while cumulative threat risks did 
not. But in this model, inhibitory control and cognitive flexibility were negative predicted by both deprivation and threat risk indices.

The second hypothesis regarding emotional and behavioral outcomes was fully supported in the risk incidence models, however, when risk was modeling risk as cumulative, our hypotheses held only for externalizing behavior in which cumulative threat but not deprivation risks predicted higher levels $(b=-0.024, S E=0.007, p<.001)$. This coefficient was in the same direction but of smaller magnitude compared to the incidence model. Interpersonal skills, approaches to learning, and attentional focus were all predicted in expected directions but by both deprivation and threat cumulative risk indices.

Finally, the third hypothesis - that math scores would be negatively predicted by both deprivation and threat incidence, was supported in this model, with coefficients in the same direction but of smaller magnitude compared to the incidence model $(b=-0.019, S E=0.005, p<$ .001 , and $b=-0.020, S E=0.006, p<.01$ for deprivation and threat cumulative risk indices, respectively).

\section{Interaction Effects between Deprivation and Threat Risks}

Our exploratory research question pertained to whether there were interactive effects between both incidence and accumulation of deprivation and threat risks. As shown in Table 4, of the 18 interaction terms assessed, only one - the interaction between the two risk indices in predicting externalizing outcomes — was statistically significant. Because this is not greater than chance, we do not interpret these results.

\section{Discussion}

This study tests a set of hypotheses concerning how different types of early adversity predicted different school readiness skills related to higher-order learning, pattern learning, and emotions and behaviors. Advancements in neurobiological developmental research are allowing 
for more a nuanced understanding of how adversity affects development, with a distinction being made between the effects of early deprivation adversity (i.e., not receiving necessary environmental inputs) and early threat adversity (i.e., feeling unsafe or threatened in one's environment). Yet research to date to develop these hypotheses has been primarily lab-based, given the nature of measuring neurobiological processes, and focused on older children. Our study bridges these findings with the literature on cumulative risk and child development (Evans et al., 2013) by testing hypotheses about the associations between exposure to deprivation and threat adversities (McLaughlin \& Sheridan, 2014; 2016) on a range of outcomes in a nationally representative sample of kindergarteners, using cognitive and behavioral indicators that may result from these underlying neurobiological processes.

Notably, in this nationally representative sample of kindergarteners, 71 and $66 \%$ of children experienced at least one deprivation and one threat risk, respectively. The original Adverse Childhood Experiences (ACE) Study (Felitti et al., 1998) found that among a sample of adults, over half experienced at least one out of seven ACEs in retrospective reporting. In a more recent study, Hunt, Slack and Berger (2017) found that 77\% of five-year old children had experienced at least one or more out of eight ACEs among a sample of high-risk children. Importantly, the way risk is operationalized varies across studies and across disciplines, and the risks included in this study departs from how ACEs are operationalized, which focus on experiences of abuse and neglect, as well as more severe household challenges (Felitti et al., 1998). Our measures of risk are more numerous and encompassing than the ACE questions, and our estimates suggest that among a national sample, young children in the United States experience a very high rate of adversity using this definition. Importantly, the majority of children experienced fewer than three risks in each domain, and children were more likely to experience deprivation-related risks than threat-related risks. More specifically, for deprivation, 
$29.0 \%$ of children had zero risks (no risk); $45.6 \%$ had $1-2$ risks (low risk), $19.9 \%$ had $3-4$ risks, and $5.5 \%$ had more than four risks (high risk). For threat, $34.2 \%$ of children had zero risks; $55.5 \%$ had $1-2$ risks, $9.9 \%$ had $3-4$ risks, and $0.4 \%$ had four or more risks. Future research may consider if these different categories are substantively more meaningful than a linear cumulative index.

We modeled both incidence and accumulation of risk. This allowed us to test exposure to risk (incidence) and the intensity of that exposure (accumulation). We found partial confirmation for our hypotheses, with the strongest support for negative relations between incidence of threat risk and emotional and behavioral outcomes, incidence of deprivation risk and early reading scores, and both threat and deprivation risks predicting lower math scores, representing pattern learning outcomes. The results were less consistent when modeling risk as cumulative. Specifically, cumulative threat and deprivation risks predicted three of the four outcomes related to emotions and behaviors, with only externalizing behaviors predicted by threat, but not deprivation, cumulative risks. The pattern of results is not as consistent as those from lab-based studies of the neural and physiological processes underlying these outcomes, which have found distinct connections between experiences of deprivation, such as neglect, with higher-order cognitive processes (e.g., Hanson et al., 2015; Sheridan et al., 2012), and experiences of threat, such as abuse, with physiological and neural structures associated with psychopathology (e.g., McLaughlin et al., 2016). This suggests that in their daily environments, children's behaviors and performance are inter-related and may be more difficult to disentangle than the underlying biological processes that drive them. Alternatively, it is possible that skills across domains are more connected in early childhood, when the foundation for many skills is being developed, and thus all domains are sensitive to any type of risk experience. Lab-based studies to date examining these issues have focused primarily on adolescents, and thus it is not possible to disentangle the 
cause of these divergent findings.

Another explanation may point to the modeling of risk as cumulative, rather than incidental. Across all models, children's outcomes were more likely to be related to both deprivation and threat risks when modeled as cumulative as opposed to dichotomous. This supports a combination of the theoretical perspectives of cumulative risk and allostatic load (McEwen, 2012), as well as adversity defined as deviations from children's expectable environments (Fox et al., 2010). More specifically, while experiences of deprivation may not directly pose stress on children the way that experiences of threat might (McLaughlin \& Sheridan, 2016), the adjustments children are required to make when experiencing a deviation from the expectable environment may result in physiological changes that affect a broad range of learning circuitry and processes (Fox et al., 2010). Recent research finds more nuanced and interrelated associations between deprivation risk and child development. Specifically, Miller and colleagues (2018) find that experiencing deprivation in early childhood predicts subsequent verbal abilities in adolescence, and verbal abilities strongly predict later internalizing and externalizing behaviors. Further investigation is needed of the interplay of children's development across different domains over time using both neurophysiological measures of learning processes, as well as cognitive and behavioral indicators, to understanding more holistically how experiences of early deprivation and threat play out across children's lives.

We found weaker support for the relations between deprivation risks and the three elements of executive function (EF) assessed. In both models, inhibitory control was predicted by both deprivation and threat risk. While contrary to our hypothesis, this is in line with a recent study that found that while exposure to violence and poverty differentially predicted children's emotion regulation and cognitive control, both predicted children's emotional inhibitory control (Lambert et al., 2017). The other two dimensions of EF-working memory and cognitive 
flexibility - were not consistently predicted across models. In the incidence of risk models, neither deprivation nor threat was a significantly predictor of these two outcomes. In the cumulative risk models, deprivation cumulative risks predicted working memory, and both deprivation and threat cumulative risks negatively predicted cognitive flexibility. This pattern of results is in line with a cumulative risk perspective, suggesting that it is the accumulation of risk, rather than the incidence of risk, that may overwhelm children's adaptive capacity in their development of these two particular elements of EF (Evans et al., 2013). Alternatively, the lack of consistent findings may partly reflect measurement issues, with recent research suggesting that elements of EF are better represented as a latent construct (Willoughby \& Blair, 2016), and that EF is unidimensional in early childhood, and multidimensional in late middle childhood and beyond (e.g., Shing, Lindenberger, Diamond, Li, \& Davidson, 2010). This points to the possibility that distinct consequences of exposure to different types of adversity may not emerge until later in childhood or adolescence.

Researchers are beginning to test and refine these hypotheses in different samples, and more attention to the pattern of relations at different developmental stages is needed. The explicit learning skills represented by EF and reading, as well as math, develop throughout childhood and adolescence and can be improved with effort and strategy, and assessment of their interplay with emotions and behaviors is needed. For example, Hanson et al. (2017) tested if general learning mechanisms account for the effects of early threat-related adversity on the development of behavior problems in a small sample of adolescents, finding that impaired associative learning partially explained the higher levels of behavioral problems among youth who suffered early adversity. Continuing to understand the links between early adversity, incidence versus accumulation, disrupted learning processes, and cognitive and behavioral outcomes is an important area for future research. 
Interpreting the results in light of their magnitude is important to understand their practical significance. We found that each additional deprivation risk was associated with approximately 0.02 standard deviations (SD) in both reading and math outcomes, and each additional threat risk associated with approximately $0.02 \mathrm{SD}$ in math outcomes. As a reference, children learn about one SD in academic skills over the course of kindergarten (Hill, Bloom, Black, \& Lipsey, 2008). Thus, for children experiencing one risk, this association may not be particularly substantive. However, these associations become larger and more practically significant when children experience multiple risks. Regarding behavioral outcomes, in our models, the significant coefficients predicting emotions and behaviors for the cumulative risk index ranged from $0.01-0.03$, and for the incidence (any) of threat risks ranged between $0.04-$ 0.06. As a reference, estimates suggest that the gap between girls and boys in kindergarten, favoring girls, is about 0.4 SD (Duncan \& Magnuson, 2011). Finally, there is not a relevant reference point for the development of and gaps in executive function skills, though the magnitude of the coefficients in these models were similar in size to those of the academic outcomes.

Finally, we do not find any evidence for interactive effects of the two domains of risk. This further supports the notion that the two are distinct in their effects on child development.

\section{Implications for Intervention}

While more research is needed to unpack the ways in which different forms of early adversity affect children's lives in the short- and long-term, our descriptive results reveal that over $70 \%$ of kindergarteners experience some form of adversity. Our analyses suggest that experiencing even just one risk is associated with poorer outcomes in children's first year of schooling. This highlights a need for more comprehensive family services during early childhood before children arrive at kindergarten. Second, we assess children's learning 
outcomes at the end of the school year, controlling for their fall scores, and find associations between risk and a range of outcomes. This indicates that during the kindergarten year, children's growth continues to be sensitive to their early deprivations and risk experiences. Importantly, many schools do in fact collect data on children's early adversity using the Adverse Childhood Experiences questionnaire (ACES Connection, n.d.), as do some pediatric offices (e.g., Burke-Harris, Marques, Oh, Bucci, \& Cloutier, 2017). More schools may want to consider collecting such data, or other checklists that cover a broader list of risk factors as early as kindergarten. Analyzing children's risk experiences by domains could allow schools to allocate more targeted supports for children in their first year of formal schooling that could lead to a more positive trajectory throughout school.

Third, the findings suggest that even in kindergarten, children's emotional and behavioral outcomes are shaped by their experiences of threat-related risks. In schools located in neighborhoods with high rates of violence (one of the risk factors measured in this study), children may feel their physical integrity is threatened. Programs in early elementary school that enhance supportive relationships with caregivers and teachers (McLaughlin \& Lambert, 2017), and those that target social-emotional development and related emotional and behavioral outcomes (e.g., Heller et al., 2017), may be particularly effective. Finally, one consistent finding across both of our models was that early reading outcomes were only predicted by deprivation (but not threat) risks. This is very consistent with decades of previous research and suggests that interventions that support children's verbal and reading skills, whether family- or school-based, will be particularly effective for children from deprived backgrounds. Schools located in lowincome neighborhoods, where children are much less likely to have access to print and books (e.g., Neuman \& Celano, 2011), or neighborhoods where children may experience lower levels of cognitive stimulation due to other factors, may consider universal school-based interventions 
focused on developing reading skills.

\section{Limitations and Conclusions}

It is important to interpret these results in light of the study's limitations. First, while we consider nine outcomes that represent different types of learning processes, we include only one measure of language learning (i.e., reading) and one measure of pattern / associative learning outcomes (i.e., math) given the availability in the dataset. Future research should include a more extensive set of complementary measures to allow for a more robust analysis of these types of outcomes. For example, Anderson and Reidy (2012) argue that most multi-dimensional EF tasks suffer from "task impurity" in that there are underlying abilities across all of the tasks, and that additional sources of information (e.g., teacher reports) should be attained to complement direct assessments. Second, we evaluated each outcome individually, knowing that children's developmental domains are correlated. Future work may consider testing these relations using structural equation modeling, where all paths between risk indices and outcomes can be modeled simultaneously. Third, while we consider two dimensions of risk, we cannot assess the frequency and severity of exposure to each of these risks. This is an important element in McLaughlin and Sheridan's (2016) model. Future research should explore these dimensions of exposure to adversity shown to be an important predictor of later life outcomes (e.g., Fisher et al., 2010). Furthermore, there is no agreed upon categorization of risk experiences as ones of deprivation or threat. This also limits the contribution of our study to the broader literature, given the range of definitions that have been used across studies. Fourth, we considered risks over the course of the kindergarten year only. Recent research has identified links between abuse and maltreatment in early life and learning and behavioral outcomes in adolescence (Hanson et al., 2017), indicating that longer longitudinal studies are necessary. Fifth, we are limited to the available questions in the ECLS-K dataset when assess children's home experiences. Research suggests that there are 
many ways that families invest in their children (e.g., Fuglini \& Yoshikawa, 2004) that are not covered in this dataset. Thus, our ability to operationalize risk factors is constrained.

Finally, this study takes a deficit-oriented approach to assessing development, as it considers only risk factors influencing development. Certainly, children facing adversity can and do display resilience (Masten, 2014). Furthering resiliency research that systematically assesses the protective factors in children's lives that promote resilience, as well as if and how protective factors may differ based on the type adversity children face, is a fruitful area for future research to inform intervention. Many of the risk factors used in this study could also be operationalized as protective factors, forming a cumulative protection index (e.g., Yoshikawa, 1994) to examine how the presence of protective factors support children's development. This would also contribute to a deeper understanding of the conditions under which the pathways from risk to outcomes operate.

One purpose of this study was to provide findings that extend the literature to a nationally representative sample and that spur future research. Ultimately, as more nuanced hypotheses about early adversity continue to be developed and confirmed with other samples of children, we can begin to draw more definitive conclusions about the pathways through which exposure to different types of adversity affects children's development across multiple domains. Such distinctions will allow for a clearer understanding of disparities across domains of development in early childhood, the types of supports children may need based on their environmental circumstances, and ultimately more strategic approaches for intervention. 


\section{References}

Amato, P. R. (2005). The impact of family formation change on the cognitive, social, and emotional well-being of the next generation. The Future of Children, 75-96.

Anderson, P.J. \& Reidy, N. (2012). Neuropsychology Review, 22, 345-360.

Bethell, C.D., Simpson, L.A., \& Solloway, M.R. (2017). Child well-being and Adverse Childhood Experiences in the United States. Academic Pediatrics, 17(7), S1-S3.

Bowen, N. K., \& Bowen, G. L. (1999). Effects of crime and violence in neighborhoods and schools on the school behavior and performance of adolescents. Journal of Adolescent Research, 14(3), 319342.

Bradley, R. H., \& Corwyn, R. F. (2002). Socioeconomic status and child development. Annual Review of Psychology, 53(1), 371-399.

Brooks-Gunn, J., \& Duncan, G. J. (1997). The effects of poverty on children. The Future of Children, $7(2), 55-71$.

Bull, R., \& Scerif, G. (2001). Executive functioning as a predictor of children's mathematics ability: Inhibition, switching, and working memory. Developmental Neuropsychology, 19(3), 273-293.

Burdette, H. L., \& Whitaker, R. C. (2005). A national study of neighborhood safety, outdoor play, television viewing, and obesity in preschool children. Pediatrics, 116(3), 657-662.

Burke Harris, N., Marques, S.S., Oh, D., Bucci, M., \& Cloutier, M. (2017). Prevent, Screen, Heal: Collective action to fight the toxic effects of early life adversity. Academic Pediatrics, 17(7), S14S15.

Busso, D. S., McLaughlin, K. A., \& Sheridan, M. A. (2017). Dimensions of adversity, physiological reactivity, and externalizing psychopathology in adolescence: Deprivation and threat. Psychosomatic Medicine, 79(2), 162-171.

Chang, L., Schwartz, D., Dodge, K. A., \& McBride-Chang, C. (2003). Harsh parenting in relation to child emotion regulation and aggression. Journal of Family Psychology, 17(4), 598-606. 
Cummings, E. M., \& Davies, P. T. (1994). Maternal depression and child development. Journal of Child Psychology and Psychiatry, 35(1), 73-122.

Davidov, M., \& Grusec, J. E. (2006). Untangling the links of parental responsiveness to distress and warmth to child outcomes. Child Development, 77(1), 44-58.

Deater-Deckard, K. (2005). Parenting stress and children's development: Introduction to the special issue. Infant and Child Development, 14(2), 111-115.

Donlan, C., Cowan, R., Newton, E. J., \& Lloyd, D. (2007). The role of language in mathematical development: Evidence from children with specific language impairments. Cognition, 103(1), 2333.

Duncan, G. J., Dowsett, C. J., Claessens, A., Magnuson, K., Huston, A. C., Klebanov, P., ... \& Sexton, H. (2007). School readiness and later achievement. Developmental Psychology, 43, 1428-1446.

Duncan, G. J., Yeung, W. J., Brooks-Gunn, J., \& Smith, J. R. (1998). How much does childhood poverty affect the life chances of children? American Sociological Review, 63(3), 406-23.

Duncan, G. J., \& Magnuson, K. (2011). The Nature and Impact of Early Achievement Skills, Attention and Behavior Problems. In G. Duncan, \& R. Murnane (Eds.), Social Inequality and Educational Disadvantage. NY: Russell Sage Foundation.

Ermisch, J., \& Francesconi, M. (2002). The effect of parents' employment on children's educational attainment. Working Papers of the Institute for Social and Economic Research, \#2002-21. Colchester: University of Essex.

Evans, G. W., Li, D., \& Whipple, S. S. (2013). Cumulative risk and child development. Psychological Bulletin, 139(6), 1342-1396.

Fisher, H. L., Jones, P. B., Fearon, P., Craig, T. K., Dazzan, P., . . Morgan, C. (2010). The varying impact of type, timing and frequency of exposure to childhood adversity on its association with adult psychotic disorder. Psychological Medicine, 40(12), 1967-1978.

Fox, S. E., Levitt, P., \& Nelson, C. A. (2010). How the timing and quality of early experiences 
influence the development of brain architecture. Child Development, 81(1), 28-40.

Furstenberg, F. F., Cook, T. D., Eccles, J., Elder, G. H., \& Sameroff, A. (1999). Managing to make it: Urban families and adolescent success. Chicago, IL: University Chicago Press.

Gabalda, M. K., Thompson, M. P., \& Kaslow, N. J. (2010). Risk and protective factors for psychological adjustment among low-income, African American children. Journal of Family Issues, 31, 423- 444.

Gershoff, E. T. (2002). Corporal punishment by parents and associated child behaviors and experiences: a meta-analytic and theoretical review. Psychological Bulletin, 128(4), 539.

Gershoff, E. T., Aber, J. L., Raver, C. C., \& Lennon, M. C. (2007). Income is not enough: Incorporating material hardship into models of income associations with parenting and child development. Child Development, 78(1), 70-95.

Green, J. G., McLaughlin, K. A., Berglund, P., Gruber, M. J., Sampson, N. A., Zaslavsky, A. M., \& Kessler, R. C. (2010). Childhood adversities and adult psychopathology in the National Comorbidity Survey Replication (NCS-R) I: Associations with first onset of DSM-IV disorders. Archives of General Psychiatry, 62, 113-123.

Gilbert, R., Widom, C. S., Browne, K., Fergusson, D., Webb, E., \& Janson, S. (2009). Burden and consequences of child maltreatment in high-income countries. The Lancet, 373(9657), 68-81. Hackman, D.A., \& Farah, M. J. (2009). Socioeconomic status and the developing brain. Trends in Cognitive Sciences, 13(2), 65-73.

Hanson, J. L., Wouter, B., Roeber, B. J., Rudolph, K. D., Davidson, R. J., \& Pollak, S. D. (2017). Early adversity and learning: implications for typical and atypical behavioral development. Journal of Child Psychology and Psychiatry, 58(7), 770-778.

Hartley, C.A., Fischl, B., \& Phelps, E.A. (2011). Brain structure correlates of individual differences in the acquisition and inhibition of conditioned fear. Cerebral Cortex, 21(9), 1954-1962.

Heleniak, C., King, K. M., Monahan, K. C., \& McLaughlin, K. A. (2018). Disruptions in emotion 
regulation as a mechanism linking community violence exposure to adolescent internalizing problems. Journal of Research on Adolescence, 28(1), 229-244.

Heller, S. B., Shah, A. K., Guryan, J., Ludwig, J., Mullainathan, S., \& Pollack, H.A. (2017). Thinking, Fast and Slow? Some Field Experiments to Reduce Crime and Dropout in Chicago, Quarterly Journal of Economics, 132(1), 1-54

Herrenkohl, T. I., Maguin, E., Hill, K. G., Hawkins, J. D., Abbott, R. D., \& Catalano, R. F. (2000). Developmental risk factors for youth violence. Journal of Adolescent Health, 26(3), 176-186.

Hill, C. J., Bloom, H. S., Black, A. R., \& Lipsey, M. W. (2008). Empirical benchmarks for interpreting effect sizes in research. Child Development Perspectives, 2, 172-177.

Hill, N. E., \& Tyson, D. F. (2009). Parental involvement in middle school: a meta-analytic assessment of the strategies that promote achievement. Developmental Psych, 45, 740.

Humphreys, K.L., King, L.S., Sacchet, M.D., Camacho, C., Colich, N.L., ...Gotlib, I.H. (2018). Evidence for a sensitive period in the effects of early life stress on hippocampal volume. Developmental Science. [E-pub ahead of print]

Jelleyman, T., \& Spencer, N. (2008). Residential mobility in childhood and health outcomes: a systematic review. Journal of Epidemiology \& Community Health, 62(7), 584-592.

Johnson, A. D., \& Markowitz, A. J. (2018). Associations Between Household Food Insecurity in Early Childhood and Children's Kindergarten Skills. Child Development, 89(2), e1-e17.

Johnson, D. R., \& Young, R. (2011). Toward best practices in analyzing datasets with missing data: Comparisons and recommendations. Journal of Marriage and Family, 73(5), 926-945.

Jones, D.E., Greenberg, M., \& Crowley, M. (2015). Early social-emotional functioning and public health: The relationship between kindergarten social competence and future wellness. American Journal of Public Health, 105(11), 2283-2290.

Kainz, K., Willoughby M. T., Vernon-Feagans L., \& Burchinal M. R. (2012). Modeling Family Economic Conditions and Young Children's Development in Rural United States: Implications for 
Poverty Research. Journal of Family and Economic Issues, 33(4), 410-20.

Kalil, A., Dunifon, R., Crosby, D., \& Houston Su, J. (2014). Work hours, schedules, and insufficient sleep among mothers and their young children. Journal of Marriage and Family, 76(5), 891-904.

Lambert, H. K., King, K. M., Monahan, K. C., \& McLaughlin, K. A. (2017). Differential associations of threat and deprivation with emotion regulation and cognitive control in adolescence. Development and Psychopathology, 29(3), 929-940.

Ma, X. (1999). A meta-analysis of the relationship between anxiety toward mathematics and achievement in mathematics. Journal for Research in Mathematics Education, 520-540.

Mahoney, 2000. School extracurricular activity participation as a moderator in the development of antisocial patterns. Child Development, 71(2), 502-516.

Masten, A. S. (2014). Global perspectives on resilience in children and youth. Child Development, 85(1), 6-20.

McCoy, D. C., Raver, C. C., \& Sharkey, P. (2015). Children's cognitive performance and selective attention following exposure to neighborhood violence. Journal of Health and Social Behavior, $56,19-36$.

McEwen, B. S. (2012). Brain on stress: How the social environment gets under the skin. Proceedings of the National Academy of Sciences, 109, 17180-17185.

McLaughlin, K. A., \& Lambert, H. K. (2017). Child trauma exposure and psychopathology: mechanisms of risk and resilience. Current Opinions in Psychology, 14, 29-34.

McLaughlin, K. A., \& Sheridan, M. A. (2016). Beyond cumulative risk: A dimensional approach to childhood adversity. Current Directions in Psychological Science, 25(4), 239-245.

McLaughlin, K. A., Sheridan, M. A., Gold, A. L., Lambert, H. K., Heleniak, C., Duys, A., .. Pine, D. S. (2016). Maltreatment exposure, brain structure, and fear conditioning in children. Neuropsychopharmacology, 41, 1956-1964.

McLaughlin, K. A., Sheridan, M. A., \& Lambert, H. K. (2014). Childhood adversity and neural 
development: Deprivation and threat as distinct dimensions of early experience. Neuroscience \& Biobehavioral Reviews, 47, 578-591.

McLoyd, V. C. (1998). Socioeconomic disadvantage and child development. American Psychologist, 53(2), 185-204.

Mehta, M. A., Gore-Langton, E., Golembo, N., Colvert, E., Williams, S. C., \& Sonuga-Barke, E. (2010). Hyporesponsive reward anticipation in the basal ganglia following severe institutional deprivation early in life. Journal of Cognitive Neuroscience, 22(10), 2316-25.

Miller, A. B., Sheridan, M. A., Hanson, J. L., McLaughlin, K. A., Bates, J. E., Lansford, J. E., ... Dodge, K. A. (2018). Dimensions of deprivation and threat, psychopathology, and potential mediators: A multi-year longitudinal analysis. Journal of Abnormal Psychology, 127(2), 160-170.

Miyake, A., Friedman, N. P., Emerson, M. J., Witzki, A. H., Howerter, A., \& Wager, T. D. (2000). The unity and diversity of executive functions and their contributions to complex "frontal lobe" tasks: a latent variable analysis. Cognitive Psychology, 41(1), 49-100.

Mol, S. E., Bus, A. G., de Jong, M. T., \& Smeets, D. J. (2008). Added value of dialogic parent-child book readings: A meta-analysis. Early Education and Development, 19(1), 7-26.

Mollborn, S., Lawrence, E., \& Root, E. D. (2018). Residential Mobility Across Early Childhood and Children's Kindergarten Readiness. Demography, 55(2), 485-510.

Mulligan, G. M., Hastedt, S., \& McCarroll, J. C. (2012). First-Time Kindergartners in 2010-11: First Findings from the Kindergarten Rounds of the Early Childhood Longitudinal Study, Kindergarten Class of 2010-11 (ECLS-K: 2011). NCES 2012-049. National Center for Education Statistics. Washington, D.C.: NCES.

Mulligan, J., \& Mitchelmore, M. (2009). Awareness of pattern and structure in early mathematical development. Mathematics Education Research Journal, 21(2), 33-49.

National Institute of Child Health and Human Development Early Child Care Research Network, \& Duncan, G. (2003). Modeling the impacts of child care quality on children's preschool cognitive 
development. Child Development, 74, 1454-1475.

Neece, C. L., Green, S. A., \& Baker, B. L. (2012). Parenting stress and child behavior problems: A transactional relationship across time. American Journal on Intellectual and Developmental Disabilities, 117(1), 48-66.

Neuman, S. B., \& Celano, D. (2011). Access to print in low-income and middle-income communities: An ecological study of four neighborhoods. Reading Research Quarterly, 46(1), 8-26.

Noble, K. G., Norman, M. F., \& Farah, M. J. (2005). Neurocognitive correlates of socioeconomic status in kindergarten children. Developmental Science, 8(1), 74-87.

Noble, K. G., McCandliss, B. D., \& Farah, M. J. (2007). Socioeconomic gradients predict individual differences in neurocognitive abilities. Developmental Science, 10(4), 464-480.

Noble, K.G., Tottenham, N., \& Casey, B.J. (2005). Neuroscience perspectives on disparities in school readiness and cognitive achievement. The Future of Children, 15(1), 71-89.

Odom, E. C., Vernon-Feagans, L., \& Crouter, A. C. (2013). Nonstandard maternal work schedules: Implications for African American children's early language outcomes. Early Childhood Research Quarterly, 28(2), 379-387.

Olds, D.L., Sadler, L. \& Kitzman, H. (2007). Programs for parents of infants and toddlers: recent evidence from randomized trials. Journal of Child Psychology and Psychiatry, 48(3/4), 355-391.

Perruchet, P., \& Pacton S. (2006). Implicit learning and statistical learning: one phenomenon, two approaches. Trends in Cognitive Science, 10(5), 233-238.

Petterson, S. M., \& Albers, A. B. (2001). Effects of poverty and maternal depression on early child development. Child Development, 72(6), 1794-1813.

Pollak, S. D., Cicchetti, D., Hornung, K., \& Reed, A. (2000). Recognizing emotion in faces: developmental effects of child abuse and neglect. Developmental Psychology, 36(5),679-88.

Pollak, S. D., Nelson, C. A., Schlaak, M. F., Roeber, B. J., Wewerka, S. S., Wiik, K. L., ... \& Gunnar, M. R. (2010). Neurodevelopmental effects of early deprivation in postinstitutionalized children. 
Child Development, 81(1), 224-236.

Raver, C. C., McCoy, D. C., Lowenstein, A. E., \& Pess, R. (2013). Predicting individual differences in low-income children's executive control from early to middle childhood. Developmental Science, $16(3), 394-408$.

Reardon, S. (2011). The widening academic achievement gap between the rich and the poor: New evidence and possible explanations. In Duncan, G., \& Murnane, G. (eds). Whither Opportunity?: Rising Inequality, Schools, and Children's Life Chances (pp. 91-111). New York: Russel Sage.

Reich, K., Culross, P. L., \& Behrman, R. E. (2002). Children, youth, and gun violence: Analysis and recommendations. The Future of Children, 12(2), 4-23.

Rhoades, B. L., Greenberg M. T., Lanza S. T., \& Blair C. (2011). Demographic and familial predictors of early executive function development: Contribution of a person-centered perspective. Journal of Experimental Child Psychology, 108(3), 638-662.

Romberg, A.R., \& Saffran, J.R. (2010). Statistical learning and language acquisition. Wiley Interdisciplinary Reviews: Cognitive Science, 1(6), 906-914. doi: 10.1002/wcs.78.

Roy, A. L., \& Raver, C. C. (2014). Are all risks equal? Early experiences of poverty-related risk and children's functioning. Journal of Family Psychology, 28(3), 391.

Royston, P. (2004) Multiple Imputation of Missing Values. The Stata Journal, 4, 227-241.

Sameroff, A. J., Seifer, R., Barocas, R., Zax, M., \& Greenspan, S. (1987). Intelligence quotient scores of 4-year-old children: Social-environmental risk factors. Pediatrics, 79(3), 343-350.

Sameroff, A. J., Seifer, R., Baldwin, A., \& Baldwin, C. (1993). Stability of intelligence from preschool to adolescence: The influence of social and family risk factors. Child Development, 64(1), 80-97. Scanlon, E., \& Devine, K. (2001). Residential mobility and youth well-being: Research, policy, and practice issues. Journal of Sociology \& Social Welfare, 28(1), 119-138.

Sénéchal, M., \& LeFevre, J. A. (2002). Parental involvement in the development of children’s reading skill: A five-year longitudinal study. Child Development, 73(2), 445-460. 
Sharif, I., Rieber, S., Ozuah, P. O., \& Reiber, S. (2002). Exposure to Reach Out and Read and vocabulary outcomes in inner city preschoolers. Journal of the National Medical Association, 94(3), 171-177.

Sheridan, M.A., Fox, N.A., Zeanah, C.H., McLaughlin, K.A., \& Nelson, C.A. (2012). Variation in neural development as a result of exposure to institutionalization early in childhood. Proceedings of the National Academy of Sciences of the United States of America, 109(32), 12927-12932.

Sheridan, M. A., \& McLaughlin, K. A. (2014). Dimensions of early experience and neural development: Deprivation and threat. Trends in Cognitive Sciences, 18, 580-585.

Sheridan, M. A., McLaughlin, K. A., Winter, W., Fox, N., Zeanah, C., \& Nelson, C. A. (2018). Early deprivation disruption of associative learning is a developmental pathway to depression and social problems. Nature Communications, 9, 2216.

Sheridan, M. A., Peverill, M., Finn, A. S., \& McLaughlin, K. A. (2017). Dimensions of childhood adversity have distinct associations with neural systems underlying executive functioning. Development and Psychopathology, 29(5), 1777-1794.

Shing, Y. L., Lindenberger, U., Diamond, A., Li, S. C., \& Davidson, M. C. (2010). Memory maintenance and inhibitory control differentiate from early childhood to adolescence. Developmental Neuropsychology, 35(6), 679-697.

Shonkoff, J. P., Garner, A. S., Siegel, B. S., Dobbins, M. I., Earls, M. F., McGuinn, L., ... \& Committee on Early Childhood, Adoption, and Dependent Care. (2012). The lifelong effects of early childhood adversity and toxic stress. Pediatrics, 129(1), e232-e246.

Smith, V. C., \& Wilson, C. R. (2016). Families Affected by Parental Substance Use. Pediatrics. Tatsuoka, K.K., Corter, J.E., \& Tatsuoka, C. (2004). Patterns of diagnosed mathematical content and process skills in TIMSS-R across a sample of 20 countries. American Educational Research Journal, 41(4), 901-926.

To, T., Cadarette, S. M., \& Liu, Y. (2001). Biological, social, and environmental correlates of 
preschool development. Child: care, health and development, 27(2), 187-200.

Towe-Goodman, N. R., Stifter, C. A., Coccia, M. A., \& Cox, M. J. (2011). Interparental aggression, attention skills, and early childhood behavior problems. Development and Psychopathology, 23(2), 563-576.

Weiss, B., Dodge, K. A., Bates, J. E., \& Pettit, G. S. (1992). Some consequences of early harsh discipline: Child aggression and a maladaptive social information processing style. Child Development, 63(6), 1321-1335.

Willoughby, M. T., \& Blair, C. B. (2016). Measuring executive function in early childhood: A case for formative measurement. Psychological Assessment, 28(3), 319.

Yeniad, N., Malda, M., Mesman, J., van IJzendoorn, M. H., \& Pieper, S. (2013). Shifting ability predicts math and reading performance in children: A meta-analytical study. Learning and Individual Differences, 23, 1-9.

Yoshikawa, H. (1994). Prevention as cumulative protection: Effects of early family support and education on chronic delinquency and its risks. Psychological Bulletin, 115, 28-54.

Zuckerman, B. (2009). Promoting Early Literacy in Pediatric Practice: Twenty Years of Reach Out and Read. Pediatrics, 124(6), 1660-1665. 
Table 1. Risk Factors, Definitions, and Sample Prevalence for Deprivation and Threat Indices

Risk definition

Prevalence

\begin{tabular}{ll}
\hline Deprivation risks \\
1 & Single parent \\
2 & Financial hardship \\
3 & Poverty \\
4 & No parent school involvement \\
& \\
5 & Low parental warmth \\
6 & No cognitively stimulating activities \\
7 & Minimal reading \\
& No child participation in \\
8 & extracurricular activities \\
& \\
9 & Maternal depression symptoms \\
10 & Household food insecurity \\
11 & High number of parental work hours \\
Threat risks \\
12 & Safety of home neighborhood \\
13 & Crime near school \\
14 & High parenting stress \\
15 & Use of corporal punishment \\
16 & Use of harsh disciplinary practices \\
17 & Parent substance use in past year \\
18 & High child mobility \\
Any risks
\end{tabular}

Any deprivation risks

Any threat risks
No partner or spouse living in household

$20.1 \%$

Serious financial problems since child was born

Living below federal poverty threshold

Parent had not attended a regularly scheduled parent-teacher conference or meeting

$25.5 \%$

$25.4 \%$

Parent indicated somewhat true or not at all true on at least one of the four parental warmth

items

Family had not participated in any of the six activities

Parent indicated never or only once or twice per week reading or looking at books with child

$9.5 \%$

$12.3 \%$

$7.6 \%$

$9.0 \%$

No parent participation in any extracurricular activities outside of school

Bottom $15 \%$ of sample of parents who indicated most of the time or a moderate amount of time on eleven depression items

$17.8 \%$

Household food insecure within the past year

$15.6 \%$

At least one parent works sixty hours or more per week

$21.3 \%$

$11.7 \%$

Big problem or somewhat of a problem to three items

$7.5 \%$

Crime is a big problem in the school neighborhood

$5.0 \%$

Parent indicated completely true or mostly true to four parenting stress items $\quad 26.8 \%$

$\begin{array}{ll}\text { Parent spanked child at least once within the past week } & 16.2 \%\end{array}$

Parent indicated using at least one of four harsh discipline practices $\quad 29.3 \%$

At least one biological parent needed help for drug or alcohol use within the past year $\quad 6.4 \%$

Child has lived in three or more places for 4 months or more since born $\quad 25.4 \%$

Child experiences at least one deprivation risk $\quad 71.0 \%$

Child experiences at least one threat risk 
Table 2. Bivariate Correlations Among Individual Risk Factors

\begin{tabular}{lllllllllllllllll}
1 & 2 & 3 & 4 & 5 & 6 & 7 & 8 & 9 & 10 & 11 & 12 & 13 & 14 & 15 & 16 & 17 \\
\hline
\end{tabular}

1 Single parent

2 Financial hardship

3 Poverty

5 Low parental warmth

6 No cognitively stimulating activities

7 Minimal reading

8 No child participation in extracurricular activities

9 Maternal depression symptoms

10 Household food insecurity

11 High number of parental work hours

12 Safety of home neighborhood

13 Crime near school

14 High parenting stress

15 Use of corporal punishment

16 Use of harsh disciplinary practices

17 Parent substance use in past year

18 High child mobility
4 No parent school involvement

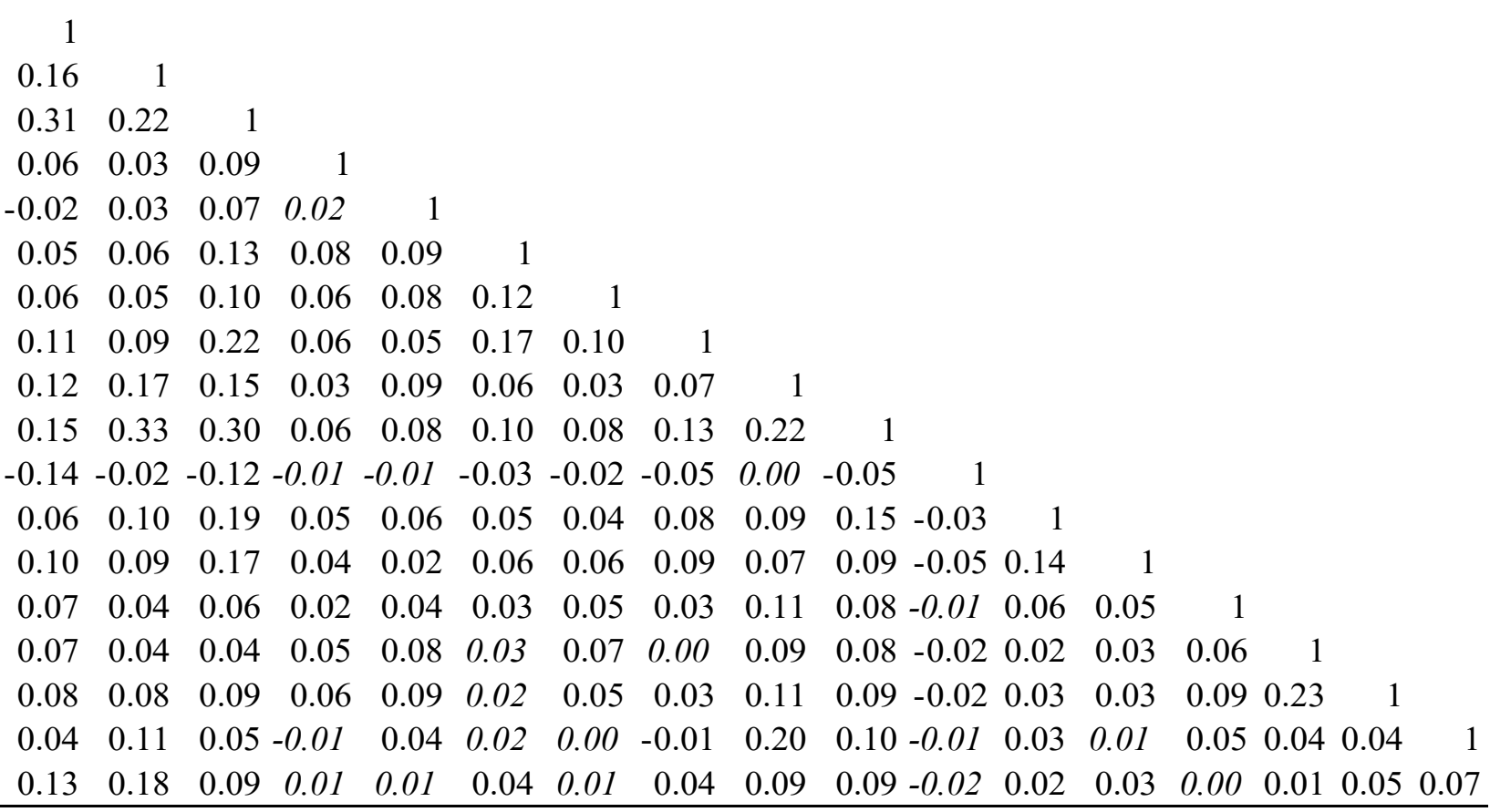

Note. Italicized numbers are not statistically significant at $p<.05$ 
Table 3. Multivariate Results of Children's Spring Outcomes as a Function of Cumulative Deprivation and Threat Risks

\begin{tabular}{|c|c|c|c|c|c|c|c|c|c|}
\hline \multirow{3}{*}{ Spring kindergarten scores } & \multirow{2}{*}{\multicolumn{5}{|c|}{ Higher-order learning outcomes }} & \multirow{2}{*}{\multicolumn{4}{|c|}{ Emotions and behaviors }} \\
\hline & & & & & & & & & \\
\hline & $\begin{array}{l}\text { Inhibitory } \\
\text { Control }\end{array}$ & $\begin{array}{l}\text { Cognitive } \\
\text { Flexibility }\end{array}$ & $\begin{array}{l}\text { Working } \\
\text { Memory }\end{array}$ & $\begin{array}{l}\text { Reading } \\
\text { Scores }\end{array}$ & $\begin{array}{l}\text { Math } \\
\text { Scores }\end{array}$ & $\begin{array}{l}\text { Externalizing } \\
\text { Behaviors }\end{array}$ & $\begin{array}{l}\text { Interpersonal } \\
\text { Skills }\end{array}$ & $\begin{array}{l}\text { Approaches } \\
\text { to Learning }\end{array}$ & $\begin{array}{l}\text { Attentional } \\
\text { Focus }\end{array}$ \\
\hline \multicolumn{10}{|l|}{ Model 1} \\
\hline Any deprivation risk experienced & $\begin{array}{c}-0.045^{* *} \\
(0.016)\end{array}$ & $\begin{array}{l}-0.016 \\
(0.020)\end{array}$ & $\begin{array}{l}-0.027 \\
(0.018)\end{array}$ & $\begin{array}{l}-0.030^{*} \\
(0.013)\end{array}$ & $\begin{array}{l}-0.030^{*} \\
(0.012)\end{array}$ & $\begin{array}{l}-0.003 \\
(0.015)\end{array}$ & $\begin{array}{c}-0.026 \\
(0.0178)\end{array}$ & $\begin{array}{l}-0.017 \\
(0.016)\end{array}$ & $\begin{array}{l}-0.031 \\
(0.016)\end{array}$ \\
\hline Any threat risk experienced & $\begin{array}{l}-0.034^{*} \\
(0.015)\end{array}$ & $\begin{array}{l}-0.030 \\
(-0.018)\end{array}$ & $\begin{array}{l}-0.024 \\
(0.016)\end{array}$ & $\begin{array}{l}-0.018 \\
(0.012)\end{array}$ & $\begin{array}{c}-0.039 * * * \\
(0.011)\end{array}$ & $\begin{array}{c}0.055^{* * *} \\
(0.014)\end{array}$ & $\begin{array}{c}-0.045^{* *} \\
(0.016)\end{array}$ & $\begin{array}{c}-0.040 * * \\
(0.015)\end{array}$ & $\begin{array}{c}-0.049 * * \\
(0.016)\end{array}$ \\
\hline $\begin{array}{l}\text { Lagged outcome } \\
\text { (Fall score) }\end{array}$ & $\begin{array}{c}0.678 * * * \\
(0.009)\end{array}$ & $\begin{array}{c}0.278 * * * \\
(0.016)\end{array}$ & $\begin{array}{c}0.493 * * * \\
(0.008)\end{array}$ & $\begin{array}{c}0.747 * * * \\
(0.009)\end{array}$ & $\begin{array}{c}0.791 * * * \\
(0.011)\end{array}$ & $\begin{array}{c}0.686^{* * *} \\
(0.009)\end{array}$ & $\begin{array}{c}0.618^{* * *} \\
(0.010)\end{array}$ & $\begin{array}{c}0.679 * * * \\
(0.008)\end{array}$ & $\begin{array}{c}0.661 * * * \\
(0.009)\end{array}$ \\
\hline Constant & $\begin{array}{l}-0.234 * \\
(0.135)\end{array}$ & $\begin{array}{l}-0.397 * \\
(0.181)\end{array}$ & $\begin{array}{c}-0.732 * * * \\
(0.148)\end{array}$ & $\begin{array}{c}0.063 \\
(0.128)\end{array}$ & $\begin{array}{l}-0.122 \\
-0.124\end{array}$ & $\begin{array}{c}0.009 \\
(0.123)\end{array}$ & $\begin{array}{c}0.230 \\
(0.146)\end{array}$ & $\begin{array}{l}-0.023 \\
(0.132)\end{array}$ & $\begin{array}{c}-0.311 * * \\
(0.141)\end{array}$ \\
\hline \multicolumn{10}{|l|}{ Model 2} \\
\hline Cumulative deprivation risk index & $\begin{array}{c}-0.019 * * * \\
(0.006)\end{array}$ & $\begin{array}{c}-0.020 * * \\
(0.008)\end{array}$ & $\begin{array}{c}-0.017 * * \\
(0.006)\end{array}$ & $\begin{array}{c}-0.023 * * * \\
(0.005)\end{array}$ & $\begin{array}{c}-0.019^{* * *} \\
(0.005)\end{array}$ & $\begin{array}{c}0.008 \\
(0.006)\end{array}$ & $\begin{array}{c}-0.016^{*} \\
(0.006)\end{array}$ & $\begin{array}{c}-0.023 * * * \\
(0.006)\end{array}$ & $\begin{array}{c}-0.027 * * * \\
(0.006)\end{array}$ \\
\hline Cumulative threat risk index & $\begin{array}{l}-0.015^{*} \\
(0.007)\end{array}$ & $\begin{array}{l}-0.022 * \\
(0.009)\end{array}$ & $\begin{array}{l}-0.013 \\
(0.008)\end{array}$ & $\begin{array}{l}-0.006 \\
(0.007)\end{array}$ & $\begin{array}{c}-0.020 * * \\
(0.006)\end{array}$ & $\begin{array}{c}0.0224 * * * \\
(0.007)\end{array}$ & $\begin{array}{c}-0.0229 * * * \\
(0.008)\end{array}$ & $\begin{array}{l}-0.015^{*} \\
(0.007)\end{array}$ & $\begin{array}{l}-0.019 * \\
(0.007)\end{array}$ \\
\hline $\begin{array}{l}\text { Lagged outcome } \\
\text { (Fall score) }\end{array}$ & $\begin{array}{c}0.676^{* * *} \\
(0.009)\end{array}$ & $\begin{array}{c}0.277 * * * \\
(0.016)\end{array}$ & $\begin{array}{c}0.493 * * * \\
(0.008)\end{array}$ & $\begin{array}{c}0.745^{* * *} \\
(0.008)\end{array}$ & $\begin{array}{c}0.789 * * * \\
(0.011)\end{array}$ & $\begin{array}{c}0.685^{* * *} \\
(0.009)\end{array}$ & $\begin{array}{c}0.616^{* * * *} \\
(0.010)\end{array}$ & $\begin{array}{c}0.678 * * * \\
(0.008)\end{array}$ & $\begin{array}{c}0.659 * * * \\
(0.009)\end{array}$ \\
\hline Constant & $\begin{array}{l}-0.228 * \\
(0.137)\end{array}$ & $\begin{array}{l}-0.350 \\
(0.180)\end{array}$ & $\begin{array}{c}-0.713 * * * \\
(0.149)\end{array}$ & $\begin{array}{c}0.083 \\
(0.129)\end{array}$ & $\begin{array}{l}-0.106 \\
(0.123)\end{array}$ & $\begin{array}{c}-0.011 \\
(0.1240)\end{array}$ & $\begin{array}{c}0.259 \\
(0.146)\end{array}$ & $\begin{array}{c}0.011 \\
(0.132)\end{array}$ & $\begin{array}{l}-0.280^{*} \\
(0.141)\end{array}$ \\
\hline Sample size & 11,050 & 11,750 & 11,750 & 11,750 & 11,750 & 11,050 & 10,950 & 11,100 & 11,050 \\
\hline
\end{tabular}

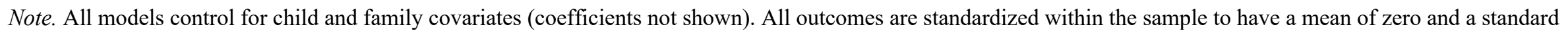
deviation of 1 . All coefficients and standard errors estimated from 20 multiply imputed datasets. Sample sizes computed by rounding the original sample size to the nearest 50 per NCES guidelines.

$* * * p<.001 . * * p<.01 . * p<.05$. 
Table 4. Multivariate Results of Children's Spring Outcomes as a Function of the interaction between Cumulative Deprivation and Threat Risks

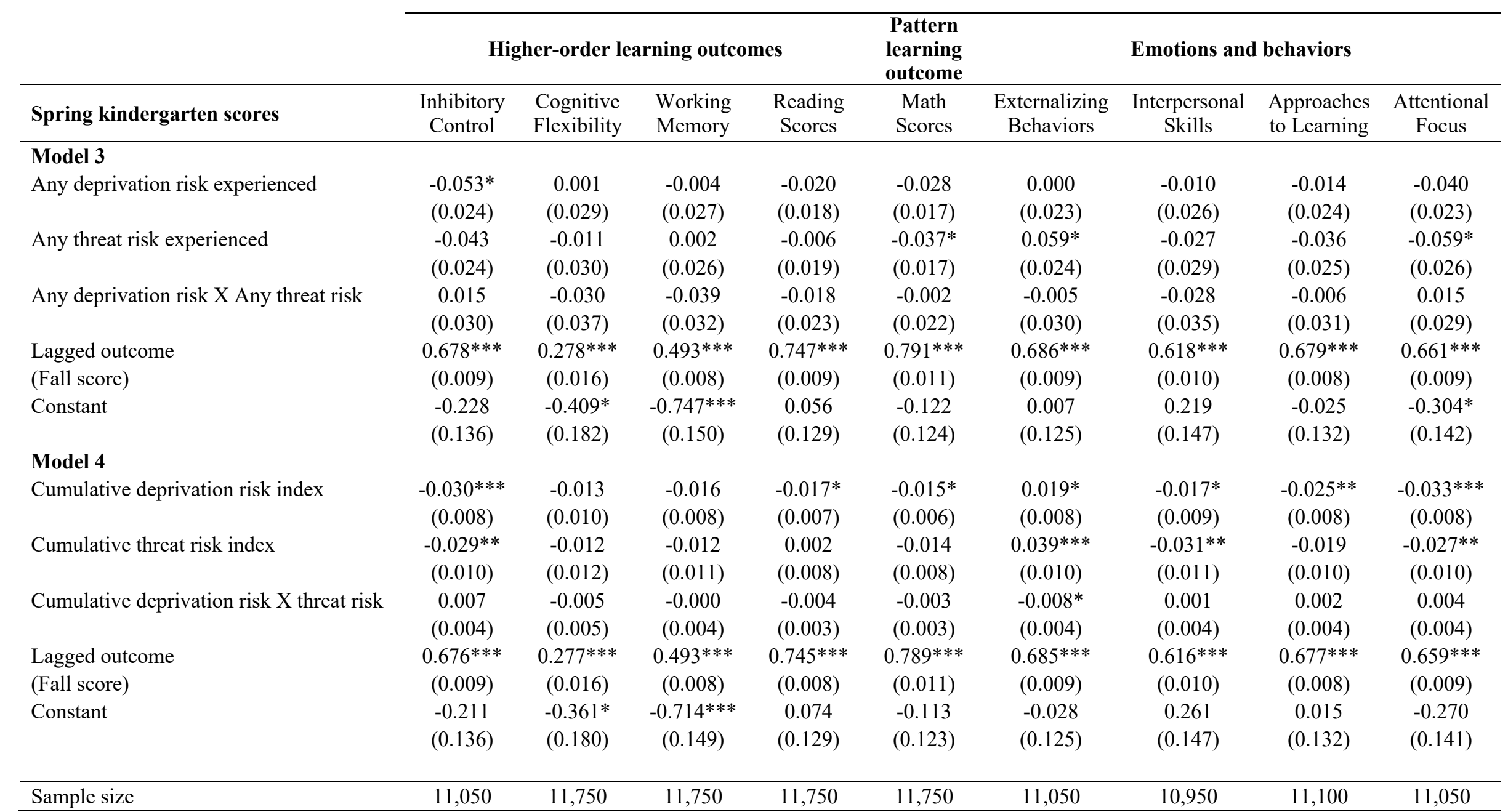

Notes. All models control for child and family covariates (coefficients not shown). All outcomes are standardized within the sample to have a mean of zero and a standard deviation of 1 . All coefficients and standard errors estimated from 20 multiply imputed datasets. Sample sizes computed by rounding the original sample size to the nearest 50 per NCES guidelines.

$* * * \mathrm{p}<.001 .{ }^{* *} \mathrm{p}<.01 .{ }^{*} \mathrm{p}<.001$ 